\title{
Clinical Psychologists' use of reflection and reflective practice within clinical work
}

\begin{abstract}
Much of the previous research regarding reflective practice has considered the training and development of reflective skills but little attention has been paid to how these are used by clinicians in practice. This study aims to understand how clinical psychologists experience reflection and reflective practice in their day to day clinical role. Six clinical psychologists currently practicing in Singapore were interviewed regarding their experiences. The interviews were analysed using Interpretative Phenomenological Analysis. Participants experienced reflection and reflective practice in many ways. Reflection helped the participants understand themselves better and how they personally impacted on their work. Reflection helped in the understanding of and engagement with clients; it was particularly important for the development of the therapeutic relationship, as well as with cases that felt 'stuck'. Finally, reflection helped participants understand their professional role as clinicians, and maintain professional and ethical standards. Generally, whilst participants valued reflection and could describe the mechanisms they used to reflect, they struggled to define reflective practice and their own process of reflection. In conclusion, participants were able to describe how using reflection and reflective practice within their clinical work benefitted them and their clients. Further investigation into this important but under researched area is required. Particular focus is needed on the challenging issue of developing a clearer definition of reflective practice.
\end{abstract}

Key Words: Clinical psychology; Professional development; Reflection; Reflective practice; Training 


\section{CLINICAL PSYCHOLOGISTS USE OF REFLECTION}

Given their scientist-practitioner training, clinical psychologists are often required and expected to use the best available scientific evidence within their clinical work. This is often generated through research findings and reflected in evidence based treatments and best practice guidelines (Stedmon \& Dallos, 2009). However, it is not clear how clinical psychologists make decisions in practice, as real life situations are often highly complex with many uncontrolled and unknown variables. Schon (1983) developed the term reflective practice to explain the process by which professionals, including psychotherapists, make difficult decisions based on more than just technical, rational or academic knowledge. He suggested that when making decisions professionals engage in two processes: reflection in action (during the event) and reflection on action (after the event). Schon (1983) argued that the concept of reflective practice was important because professionals often need to quickly make complex decisions in difficult situations without access to all available information. Therefore, technical knowledge (for example, cognitive behavioural theory) is not enough to enable professionals to make sound decisions. In this way, reflective practice can be seen as a reaction against professionals becoming overly simplistic and technique driven in their application of knowledge (Thompson \& Pascal, 2011).

Clinical psychology has been slow to embrace the concept of reflective practice due to its positivist approach within behavioural science (Bennett-Levy, 2003; Lavender, 2003). Another difficulty in the application of reflective practice is the issue of developing a definition of reflective practice, which has proved difficult due to the conceptual nature of the area (Mann, Gordon \& Macleod, 2009). Gillmer and Markus (2003) suggest part of the problem is that reflection is an atheoretical construct. Given this, many different conceptualisations of reflective practice have been proposed. Lavender (2003) contributed to the field by suggesting that reflective practice might involve four processes. Schon's (1983) 


\section{CLINICAL PSYCHOLOGISTS USE OF REFLECTION}

original two, reflection in action and reflection on action, and reflection about impact on others, and reflection about self. In contrast Sheikh, Milne, and MacGregor (2007) argue that the concept is too vague and therefore developed a related definition and model of 'personal professional development' (PPD) with a stronger focus on competency development.

Despite the difficulties with defining reflective practice, the field of clinical psychology, particularly in the United Kingdom (UK), has increasingly valued the concept, particularly in the area of clinical training (Knight, Sperlinger, \& Maltby, 2010; Binks, Jones \& Knight, 2013). The British Psychological Society (BPS) states that psychologists should be "cognisant of the importance of self-awareness and the need to appraise and reflect on their own practice" (BPS, 2008, p. 8).

Clinical Psychology training courses have taken different approaches towards promoting reflective competencies and skills including reflective groups, accessing personal therapy, reflective writing, and the use of a mentor during training (Brown, Lutte-Elliott, \& Vidalaki, 2009; Bolton, 2003; Gilmer \& Markus, 2003; Wigg, Cushway, \& Neal, 2011). There is evidence to suggest that trainees and clinical psychologists find reflective practice useful. Knight et al (2010) evaluated the impact of one training course's reflective practice groups, on subsequently qualified clinical psychologists. The groups were seen as valuable for the majority of participants. Whilst this study is of value, one critique of the research body as a whole is that it nearly exclusively focuses on whether clinicians (nearly always trainees) find reflection helpful, but not on how they use reflective practice, how they find it helpful or what, if any, benefit it has to their practice (Wigg, Cushway \& Neal, 2011). 


\section{CLINICAL PSYCHOLOGISTS USE OF REFLECTION}

Given the challenges of definition, there are no agreed approaches regarding how to measure reflective practice. Therefore, an exploratory qualitative approach would be particularly useful to explore how clinical psychologists experience and account for the role of reflection and reflective practice in their practice. Finally, most writing about reflective practice has come from perspectives in Europe, especially the UK, and North America. Given that clinical psychology is an international discipline developing quickly outside of these regions, it would be useful to gain perspectives from regions where the profession is emerging, such as Singapore (Tan, 2002). Whilst very little research into reflective practice and healthcare has been conducted within an Asian context, the utility of the concept has been considered relevant and potentially useful (Lim \& Low, 2008; Nishigori \& Sriruksa, 2011).

This study aims to explore clinical psychologists' experience and use of reflective practice within their clinical role so as to address issues of practice, training, and the on-going difficulties with establishing an overarching definition or theory in this area.

\section{Method}

\section{Design}

An Interpretive Phenomenological Analysis (IPA) approach was used for data collection and analysis (Smith, Flowers \& Larkin, 2009). IPA explores how people make sense of their experiences and is concerned with the nature of phenomena instead of what accounts for such phenomena. It is influenced by three key areas of the philosophy of knowledge: phenomenology, hermeneutics, and idiography. IPA is phenomenological as it 


\section{CLINICAL PSYCHOLOGISTS USE OF REFLECTION}

focuses on understanding the meaning of human experience and reflecting on the significance of these experiences. From hermeneutics, or the theory of interpretation, IPA pays close attention to the interaction involved when people are doing research with other people, recognizing the implications of the researcher's own point of view. IPA is idiographic as it is committed to understanding phenomena at an individual level, in a specific context. These theoretical underpinnings of IPA closely align with the area under investigation, as the concept of reflective practice has itself been linked with phenomenology (Cushway, 2009). Smith et al (2009) recommend small sample sizes for IPA studies of between three and six participants to allow for the analysis to meet the phenomenological, hermeneutic, and idiographic underpinnings of IPA. .

\section{Participants}

Six clinical psychologists (five female) who had undertaken post-graduate training in clinical psychology and met the standards of the Singapore Psychological Society (SPS) to practice in Singapore were interviewed. The average length of time since completing their professional training (either Masters or Doctorate in Clinical Psychology) was 8 years (range 3 - 12 years). Two participants completed their post-graduate training in Singapore, while four participants completed their training abroad (three in Australian universities). The participants were working in a clinical capacity in local hospitals, academic institutions, and private practices; all the participants worked with either children or adult populations and spent between 40 to 80 percent of their time on clinical work that included contact hours, note writing, team meetings, and supervision. 


\section{Interviews and Procedure}

Following ethical approval from James Cook University's ethics committee, all psychologists who fulfilled the inclusion criteria were identified from the Singapore Register of Psychologists list on the SPS website. Potential participants were invited, via email, to participate in the study. After providing informed consent, participants were interviewed individually by the first author, who was a UK trained qualified clinical psychologist who had been working in Singapore for 18 months prior to the interviews. His training had involved significant reflective practice components. Interviews were semi-structured, lasting approximately 60 minutes. An interview schedule that had been developed through a pilot interview guided the interviews. The schedule included topics such as: the participant's clinical role; how the participant made clinical decisions, how they experienced reflective practice and being reflective in their clinical roles, how their reflective practice developed and their overall understanding of reflection and reflective practice. Interviews were audio taped and transcribed verbatim.

\section{Process of Analysis}

Each interview transcript was analyzed separately. Authors followed the IPA analytical process described by Smith et al. (2009). The first stage of the analysis involved intensively reading a participant's account several times to gain familiarity. Notes were written on the right margin of the transcript to summarize and describe what had been said (descriptive comments), comment on the use of language (linguistic comments), and make initial interpretations (conceptual comments). All three authors were involved in this process 


\section{CLINICAL PSYCHOLOGISTS USE OF REFLECTION}

and regularly discussed their ideas and interpretations of the transcripts to ensure that their accounts were clearly linked to the source material and that they were in agreement. In contrast to the first author the second and third authors were Singaporean undergraduate psychology students with limited experience of reflective practice and therefore approached the data without significant assumptions. The second stage of analysis involved re-reading the individual narratives and the interpretative comments to develop emergent themes that captured the links between descriptive, linguistic, and conceptual comments. Emergent themes were reviewed by at least two of the authors, to consider how they could be clustered to form sub-themes, and then super-ordinate themes, which captured the essence of the participants' experiences. Some emergent themes were discarded due to lack of importance or coherence with other emergent themes. Once super-ordinate themes were developed, quotes were found to illustrate each theme and transcripts were re-read to consider how well the themes accounted for the participants' overall experience. This process was repeated with each transcript.

The final stage involved all authors looking for patterns across participants; the superordinate themes and corresponding sub-themes of all participants were collectively analyzed. Shared experiences within the group of participants were carefully considered and a structured list of final super-ordinate themes assembled.

\section{Results}

Four super-ordinate themes were developed to account for how clinical psychologists experienced reflective practice within their working roles. Each theme will be described and direct quotes from the participants will illustrate the theme. Quotes from participants have been corrected grammatically for presentation purposes. As participant experiences varied 
CLINICAL PSYCHOLOGISTS USE OF REFLECTION

within each theme both the similarities and differences between participant accounts will be described. The first theme accounts for how participants experience reflective practice whilst the last three themes more directly explore how participants felt they used reflection and reflective practice in their working roles.

\section{Reflecting on Reflection}

This theme explored how participants reflect, how their reflective practice developed, and the challenges participants face defining and describing reflection. Participants experienced reflecting in two distinct ways. Participant 1 reported that: When you talk about reflection, I think there are two different levels... firstly with yourself, secondly with consultation with others.

When reflecting with themselves, participants used materials such as case notes, audio tapes of sessions, diaries and journal articles. Participants reflected with others through peer supervision and consultation with senior colleagues. Participants often had similar views regarding how their reflective practice developed. Initially, reflection did not occur when things were 'going right' (Participant 6). Instead, participants discussed how they started reflecting only when they encountered clinical difficulties.

... when I came into this field, where you see you have unsuccessful cases, then you start to think a bit more... reflecting a little more and you see the benefit of it. So that's why you keep doing it (Participant 2). 
CLINICAL PSYCHOLOGISTS USE OF REFLECTION

Reflective practice was described as a process that gradually evolved, particularly as support systems, such as supervision, reduced.

I could see the pattern where supervisors are becoming less and less hands on, so more reflection on my part in order to generate like a case formulation, a lot of thinking, using past experiences, cases and so on and building upon it and then to a point where supervision or regular or consistent supervision, like weekly meetings is not necessary, but only on occasions... for me the process, it has been very gradual in terms of reflection, on how much to reflect and what to reflect and how many layers to reflect (Participant 4).

Participants found it challenging to define and describe what reflection is. Most participants found reflection hard to articulate, using metaphors to describe what reflection is and often resorting to providing concrete examples of reflection to address conceptual questions. One participant described how he experiences reflection as being similar to driving a car.

It's just like driving. You know, when you first drive, you keep a lookout on everything on the road. But now, because I've been driving for such a long time, I step on the accelerator, put on the gear, and the next moment I realise, I'm home... What happened in between? I don't know... it's just like everything is automatic (Participant 1).

For Participant 1, it appeared that the process of reflection had become internalized and automatic and this may explain why he found it hard to describe. Other participants experienced reflection in a similar way. Participant 6 reported that: 'Because of the fact 
that I did it so often with so many clients that it is almost quite unconscious the way that I approach it'.

Even though participants faced several challenges reflecting on reflection, they reported that reflective practice is a process that will continue to benefit them throughout their careers. Participant 3 reported that: 'I think this is something that I will continue doing for a long time. This is something I will not forget to do... it's been very, very useful'.

\section{Knowing Myself and My Impact}

All of the participants reported that reflection allows them to learn more about themselves. Reflection helped participants manage personal feelings, such as anxiety and inadequacy, and their impact on others. Reflective practice enabled participants to better understand themselves as well as their impact on the people around them.

It's just like for personal development... you get to know a bit more about yourself which you didn't - you wouldn't know until you really think through it..., it helps me to understand a bit more about myself... who I am and what my strengths and weaknesses are (Participant 2).

Personal weaknesses elucidated by reflective practice aroused feelings of anxiety and inadequacy for some. However, simultaneously, participants often felt that reflective practice was a means of managing troubling or negative feelings such as self-doubt. One participant described how, when managing anxiety reflection enhances self-care. 
... I do tend to be quite anxious and you know I am aware of that, so my perception is quite skewed to a certain extent... so just for me to at the end of the night or the end of the week to just pull myself back and say, what's going on here, so that I don't stress myself out unnecessarily and to tell myself, you know, slow down, I don't need to pressure myself like that (Participant 3).

Reflective practice increased awareness that personal issues may have an influence on others. Participants talked about the problems they faced when they were unaware of themselves and their impact. One participant discussed how reflective practice promotes selfawareness and prevents personal issues from manifesting 'in ways that are not helpful' (Participant 5).

If you're not doing any reflection then you've cut yourself off from what you're feeling about some things, and if you're not aware of it then probably that is playing out in ways that are not helpful. So, I think self-reflection, it does prompt us to see... we may be struggling with our own issues (Participant 5).

Consequently, participants believed that being able to understand the impact that they have on others helped them to feel that they were making better decisions in their clinical work.

I would say that it's a process that would ultimately try to generate a level of awareness that we previously had not known. The awareness would be in the form of why we do what we do, whether it's in session, outside session or in other areas of work... The 
awareness would be in terms of the impact that we have, or better still the layers of impact that we have on the people around us... so that in the future, after reflecting and having reached a certain amount of reflection, we will be able to make wiser decisions, choices about how we respond (Participant 4).

\section{My Client and Our Relationship}

Five of the six participants reported that reflective practice deepened their understanding of their clients. This was considered to be beneficial for therapeutic relationships as it enhanced the connection between participants and their clients. However, the impact of counter transference within their relationship with clients was a cause for concern for some participants.

...it's not easy, because when you do your psychotherapy, there are just so many balls to juggle. You're wondering about the next question to ask, you're checking the patient for transference, and at the same time, you're checking yourself for counter transference. There are a lot of balls to juggle. It's not easy to be a good reflective therapist (Participant 1).

Although participants were aware that managing transference reactions is important, this was experienced as difficult to reflect on as there are multiple factors that need to be simultaneously considered during therapy. Participants discussed how not being reflective regarding the client can cause difficulties during a session. 
CLINICAL PSYCHOLOGISTS USE OF REFLECTION

... it would be really easy for the clinician to go off tangent from the client... what I mean is if we're not aware of what's going on...then there could be a lot of things between the space of you and me. And then it may affect the connection... we may not even be able to predict what might happen because of the disconnection (Participant 4).

I think we would be doing work quite blindly if we don't sit back and reflect on the things that we've done. I think we'd just be moving along... I think we would be very unaware of issues and if we're unaware of issues in the therapy or in the therapeutic relationship, we may not be doing the work that is meant to be helpful for the client. I think, you know, I'd end up being more harmful than helpful (Participant 3).

Some participants highlighted that reflection seemed to happen more regularly when their clients did not appear to be improving or when they felt 'stuck' (Participant 4).

I knew that she wasn't moving in any direction at all... so in a way we were both, you know, in a place where we weren't making progress... that's one of the places where I did a lot of reflection on what can be done (Participant 5).

Overall, participants felt that reflection helped them increase their ability to understand their clients' perspective which helped them move forward with difficult cases.

... it helps to put things in perspective. It helps to bring to play all other things that... might account for a particular behaviour or outcome... so [I] have a more balanced 
perspective. Sometimes accepting that... there may be factors that are beyond my control, that are accounting for whatever I'm seeing (Participant 5).

\section{My Professional Identity and the Roles that I Need to Fulfill}

Five participants experienced reflective practice impacting on their understanding of their professional identity and the multiple roles that they needed to fulfill in their work. For example, participant 4 explained how her working context can be complex, causing her to take on various roles and responsibilities. Acting not only as a clinician, but also as a manager and consultant, she described herself as being placed in situations where she has to 'wear several hats'. She reported that: 'As a psychologist I am not just functioning as a clinician... I am required to do the different areas, which are not taught in school or in training' (Participant 4).

She explained how reflecting on past experiences helped her manage the difficulties she encountered in her numerous roles as a psychologist.

... so when I do that, I can apply very quickly. I will be able to run through different ideas about how I had applied those strategies that were given to me in the past and then now I will try it here and by doing that, I didn't need to ask anyone I could just draw from there first (Participant 4). 


\section{CLINICAL PSYCHOLOGISTS USE OF REFLECTION}

Some participants discussed how reflective practice was important for their 'professional development' (Participant 2). For example, one participant talked about how reflective practice allows her to ensure high standards of professional practice by improving her skills.

Initially I was very concerned about the skills... I wasn't as concerned with the outcome because I was honing my skills, so I was focused on that. When I felt like I was a bit more competent with my skills and my intervention then I became concerned about the outcome, so when I became concerned about the outcome, I realised I had to reflect (Participant 6).

Participant 6 suggested that the development of reflective skills can be progressive, with reflective practice improving and increasing as she advanced in her career. Another participant spoke about the development of his reflective practice, particularly for ensuring professional and ethical practice, since he received his professional training.

It has helped me to stay on the straight and narrow... especially when ethical issues pop up. I can now reflect a lot more, I can consult the issue from my more senior colleagues and I talk to them, and it helps. Reflection has also caused me, I think, to improve my skill level (Participant 1).

Participant 6 discussed how less contact with a supervisor has caused her to spend more time reflecting on ethical issues, indicating that reflection may increase in the absence of a formal 'sounding board'. She reported that reflection 'is about making sure I am doing the right thing and perhaps being ethical, to so I feel I need to invest more time and to think that am I actually, really, truly doing the right thing'. (Participant 6). 


\section{Discussion}

This study investigated how clinical psychologists use reflection and reflective practice within their clinical work. An IPA approach generated an in-depth understanding of how the participants experienced using these concepts in their role through the development of four themes.

The first theme, reflection on reflection, provides context through which to make sense of the other themes and demonstrates how participants can describe the development of their reflective skills and how they engaged in reflection yet simultaneously struggled to define reflection or account for the processes involved when they were being reflective. The many ways in which the participants reflected, both on their own and with others, were generally consistent with other published accounts (Bolton, 2003; Paula, 2003). Less commonly reported within the literature was the idea that reflection was initially undertaken when the participants encountered clinical difficulties, but with time, reflections took on a wider, less problem focused scope.

Whilst able to describe how they reflected, participants experienced significant difficulty trying to describe what reflective practice is, particularly, how they account for their reflective practice and clinical decision making. This supports the criticisms of the term reflective practice made by Sheikh et al. (2007). Interestingly, metaphor was used by some participants and this strategy has been used before to try to define reflective practice (Cushway \& Gatherer, 2003; Paula, 2003). Part of the difficulties regarding accounting for 


\section{CLINICAL PSYCHOLOGISTS USE OF REFLECTION}

and describing reflection might relate to the lack of agreed definitions regarding what reflection is and the lack of focus on developing theory in the area (Thompson \& Pascal, 2011). Whilst participants seemed to share this uncertainty, they simultaneously expressed, the high value that they attributed to reflection and reflective practice. This apparent mismatch might explain why clinical psychology training courses have developed such varying approaches to developing reflective practice (Gillmer \& Marckus, 2003; Sheikh et al, 2007), whilst simultaneously little research has been reported on how clinicians actually use reflective practice.

Participants drew attention to the slow and uneven development of reflective practice skills which continued after professional training had finished. As they practised with more autonomy, reflection played a role in helping participants maintain ethical and professional standards. Through the process of reflection, participants seemed to act as an internal supervisor to themselves and to be able to consider the appropriateness of their decisions in light of professional and ethical standards.

The theme 'knowing myself and my impact' suggested that reflective practice was a process for understanding the self, including personal beliefs and ideas and for having strategies in place to manage these and enhance self-care. Participants felt that they needed to know themselves well to be able to work effectively within their clinical roles. This theme supports Lavender (2003) who suggested that one reflective process involves understanding the self and O'Loughlin (2003) who suggested that clinicians need to understand their own motivations for undertaking clinical work. It also begins to address concerns raised by Mann et al. (2009) that there is no evidence linking reflection to increased self-awareness. Most 


\section{CLINICAL PSYCHOLOGISTS USE OF REFLECTION}

importantly, how this theme benefited the participants was linked to how the third theme benefited their practice in that understanding the self allowed the psychologists to make better decisions when working with clients and other professionals.

The third theme, 'My client and our relationship', demonstrated ways in which clinical psychologists directly can use reflection in their clinical work. This often centered on the core components of clinical work, such as building a strong relationship and increasing empathy. Participants appeared to be using reflection and their ability to understand themselves, to attune more fully with their clients and their distress (Stedmon \& Dallos, 2009). This potentially has important links to the training of reflective skills. For example, Sheikh et al. (2007) suggest that their PPD groups aim to increase professional effectiveness; improving the trainee psychologist's ability to attune to their clients may be one example of how this process happens.

Reflection and reflective practice appeared to be used by participants to enable them to make sense of their client's presentation and perspective. This bore a close relationship to the concept of psychological formulation, which internationally is considered a core competency of the profession and is the process that psychologists use to make sense of their clients’ problems (American Psychological Association, 2005; Division of Clinical Psychology [DCP], 2011). Page, Stritzke, and McLean (2008) and Stedmon and Dallos (2009) have considered the role of reflection in the development of formulation skills; the current research builds on this by showing how psychologists report that they are using reflection in their work as part of the formulation process. Participants made special mention of the value of reflection as part of the process of developing a formulation when working with cases that they found challenging or perceived as 'stuck'. 
All participants strongly reported that reflective practice had a positive impact on both their clinical behaviour and on their care of clients. This is significant as a recent review suggests that the teaching of reflective practice has not been shown to have a positive impact in these areas (Mann, Gordon, \& MacLeod, 2009). However further evidence is required regarding the impact of reflective practice and therefore it is important that more formal quantitative research methods are used within the area. This may enable reflective practice to more fully integrate into the evidence based practice movement (Fago, 2009).

The final theme suggested that reflective practice aided the development and management of a professional identity and role often within complex organisational systems. This theme has parallels to the writings of Hughes (2013) who considers how critical reflection has deepened her understanding of how she links her profession role/identity (as an educator) with her morality. The idea of reflective practice impacting on professional identity has not been regularly considered within previous clinical psychology literature. However, reflecting on one's own role and how to balance competing demands seems likely to become more important as clinical psychologists are increasingly asked to take on supervisory, consultation, and management roles (Lavender \& Paxton, 2004). Thus, reflective practice curriculums may benefit from an increased focus on professional roles and identity as a core part of the development of reflective practice.

Taken together, these themes offer a clearer articulation than previously published work of how clinical psychologists report to find reflective practice helpful in their daily 
CLINICAL PSYCHOLOGISTS USE OF REFLECTION

work and the impact that they feel it makes on their practice. In this way, this paper addresses some of the critiques of the literature discussed by Wigg et al (2011).

\section{Strengths and Limitations}

Given the self-selecting sample and inherent difficulties in generalising qualitative findings, the current findings should be seen as a way of understanding how these clinical psychologists understand and use reflection and reflective practice in their work. The extent to which this represents the profession more widely requires further investigation using multiple research methods. One particular limitation of the current study is the lack of homogeneity in terms of the training backgrounds of the sample, making it difficult to determine the extent to which training impacted on how the participants viewed their current experience of reflective practice.

As accounted for in the first theme, one difficulty in carrying out research in this area is the lack of a precise definition of reflective practice. This causes a barrier to developing knowledge and theory in the area, as the lack of a clear definition of reflective practice makes it hard for professionals to discuss and describe themselves engaging in reflection, which only serves to further hinder the development of a workable definition. Nevertheless, this research demonstrates that qualitative research methods, and in particular phenomenological approaches, are likely to be particularly helpful.

Positively, this research has a different focus to most of the previous research in the field which has focused on issues surrounding the training of reflective practice. Participants discussed how their reflective practice developed but the main focus concerned how it 
benefits them within their day to day role. Given that training in the development of reflective practice is designed to improve clinical practice, such a focus is important and has highlighted ways that clinicians experience reflection. Also, a clearer understanding of how clinicians experience their current practice should enable the development of clearer constructs in the area.

\section{Future Research}

The issue of the definition of reflective practice need to be considered more fully. Writings in this area have often been from education providers. Therefore, interviewing larger numbers of clinicians regarding their understanding of reflective practice might provide a useful step towards developing a future definition of reflective practice.

One of the difficulties that participants in the current study experienced was trying to describe in detail how they use reflective practice in their day to day experience, for example during decision making. Future research might be able to involve clinicians filming clinical sessions and then, soon afterwards, accounting for and commenting on the decisions they made and the knowledge and experience they drew on when making those decisions. A similar approach has been recently used successfully with trainee psychologists (Burgess, Rhodes \& Wilson, 2013) and could be extended more broadly to include fully qualified clinicians from a range of theoretical backgrounds.

Finally, if research were to further understand how clinicians were using reflective practice in day to day practice, research that focuses on the client's experience of these processes would further demonstrate its impact. Whilst arguments continue (e.g. Fago, 2009; 
Zeldow, 2009) regarding the relative importance of evidence based approaches versus more reflective approaches, the client's perspective needs to be more clearly conceptualised.

\section{Conclusion and Implications}

Reflection and reflective practice were highly valued by the psychologists in this study and were used on a day to day basis. Reflective practice was useful for participants to: better understand themselves; work more closely with their clients; manage challenging clinical situations; be able to be aware of their professional roles and to maintain appropriate professional and ethical standards. However, participants found it difficult to define reflective practice or to describe the process of reflection.

Reflective practice is an important component of the work of practicing clinical psychologists. The experiences of clinicians will need to be better understood to enable the development of theory in the area and facilitate the incorporation of reflective practice into the training of clinical psychologists.

\section{References}

American Psychological Association. (2005). Evidence-based practice in psychology. American Psychologist, 61 (4), 271-285.

Bennett-Levy, J. (2003). Reflection: A blind spot in psychology? Clinical Psychology, 27, $16-19$. 
Binks, C., Jones, F. W. \& Knight, K. (2013). Facilitating reflective practice groups in clinical psychology training: a phenomenological study. Reflective Practice, 14(3), 305-318.

British Psychological Society (BPS). (2008). Criteria for the accreditation of postgraduate training programmes in clinical psychology. Leicester: British Psychological Society.

Bolton, G. (2003). Lift the box lid: reflective writing for professional development. Clinical Psychology, 27, 34-38.

Brown, D. Lutte-Elliott, A., \& Vidalaki, V. (2009). Learning to reflect: trainees' perceptions of case discussion groups during a clinical psychology training course. Clinical Psychology Forum, 204, 41- 46.

Burgess, S., Rhodes, P., \& Wilson, V. (2013). Exploring the in-session reflective capacity of clinical psychology trainees: An interpersonal process recall study. Clinical Psychologist, 17, 122-130.

Cushway, D., \& Gatherer, A. (2003). Reflecting on reflection. Clinical Psychology, 27, 6- 10.

Cushway, D. (2009). Reflective practice and humanistic psychology: The whole is more than the sum of the parts. In J. Stedmon \& R. Dallos (Eds.), Reflective Practice in Psychotherapy and Counselling (pp73-92). Berkshire: McGraw-Hill Education. 
CLINICAL PSYCHOLOGISTS USE OF REFLECTION

Division of Clinical Psychology (2011). Good practice guidelines on the use of psychological formulation. Leicester, UK: British Psychological Society.

Fago, D. P. (2009). Comment: The evidence-based treatment debate: Toward a dialectical rapprochement. Psychotherapy Theory, Research, Practice, Training, 46(1), 15-18.

Gilmer, B., \& Marckus, R. (2003). Personal professional development in clinical psychology training: Surveying reflective practice. Clinical Psychology, 27, 20- 23.

Hughes, B. H. (2013). Making sense of professional identify through critical reflection: a personal journey. Reflective Practice, 14(3), 336-347.

Knight, K., Sperlinger, D., \& Maltby, M. (2010). Exploring the personal and professional impact of reflective practice groups: A survey of 18 cohorts from a UK clinical psychology training course. Clinical Psychology and Psychotherapy, 17, 427-437.

Lavender, T. (2003). Redressing the balance: The place, history and future of reflective practice in clinical training. Clinical Psychology, 27, 11-15.

Lavender, T., \& Paxton, R. (2004). DCP Workforce planning advisors: Estimating the applied psychology demand in adult mental health. Leicester: British Psychological Society.

Lim, P. H., \& Low, C. (2008). Reflective practice from the perspectives of the Bachelor of nursing students in international medical university (IMU). Singapore Nursing Journal, 35 (3), 6- 13 . 
Mann, K., Gordon, J., \& MacLeod, A. (2009). Reflection and reflective practice in health professions education: a systematic review. Advances in Health and Science Education, 14, $595-621$.

Nishigori, H., \& Sriruksa, K. (2011). Asian perspectives for reflection. Medical Teacher, 33, $580-581$.

O'Loughlin, S. (2003). Attending to the patient within us. Clinical Psychology, 27, 24-26.

Page, A., Stritzke, W.G.K., \& McLean, N.J. (2008). Toward science-informed supervision of clinical case formulation: A training model and supervision method. Australian Psychologist, 43(2), 88-95.

Paula, C. (2003). Bubbles in a pond. Reflections in Clinical Practice. Clinical Psychology, 27, 27-29.

Schon, D. F. (1983). The reflective practitioner. New York: Basic Books.

Sheikh, A. I., Milne, D. L., \& MacGregor, B. V. (2007). A model of personal professional development in the systematic training of clinical psychologists. Clinical Psychology and Psychotherapy, 14, 278-287.

Smith, J. A., Flowers, P., \& Larkin, M. (2009). Interpretative phenomenological analysis. London: Sage Publications Ltd. 
Stedmon, J., \& Dallos,R. (2009). Reflections on reflections. In J. Stedmon \& R. Dallos (Eds.), Reflective Practice in Psychotherapy and Counselling (pp73-92). Berkshire: McGraw-Hill Education.

Tan, A.G. (2002). Development of psychology in Singapore. In Tan, A.G., \& Goh, M. (Eds.), Psychology in Singapore: Issues of an emerging discipline (pp. 3-19).

Singapore, Singapore: McGraw-Hill.

Thompson, N., \& Pascal, J. (2011). Reflective practice: an existentialist perspective. Reflective Practice, 12(1), 15-26.

Wigg, R., Cushway, D., \& Neal, A. (2011). Personal therapy for therapists and trainees: a theory of reflective practice from a review of the literature. Reflective Practice: International and Multidisciplinary Perspective, 12 (3), 347-359.

Zeldow, P. B. (2009). In defence of clinical judgement, credentialed clinicians and reflective practice. Psychotherapy Theory, Research, Practice, Training, 46(1), 1-10. 